Wilfrid Laurier University

Scholars Commons @ Laurier

Kinesiology and Physical Education Faculty

Publications

Kinesiology and Physical Education

6-1994

\title{
Body Talk: Male Athletes Reflect on Sport, Injury, and Pain
}

\author{
Kevin Young \\ University of Calgary \\ Philip White \\ McMaster University \\ William McTeer \\ Wilfrid Laurier University, bmcteer@wlu.ca
}

Follow this and additional works at: https://scholars.wlu.ca/kppe_faculty

\section{Recommended Citation}

Young, Kevin; White, Philip; and McTeer, William, "Body Talk: Male Athletes Reflect on Sport, Injury, and Pain" (1994). Kinesiology and Physical Education Faculty Publications. 6.

https://scholars.wlu.ca/kppe_faculty/6

This Article is brought to you for free and open access by the Kinesiology and Physical Education at Scholars Commons@ @aurier. It has been accepted for inclusion in Kinesiology and Physical Education Faculty Publications by an authorized administrator of Scholars Commons @ Laurier. For more information, please contact scholarscommons@wlu.ca. 


\section{Body Talk: Male Athletes Reflect on Sport, Injury, and Pain}

\author{
Kevin Young \\ University of Calgary
}

\author{
Philip White \\ McMaster University
}

\author{
William McTeer \\ Wilfrid Laurier University
}

This paper examines how participation in physically demanding sport, with its potential and actual injurious outcomes, both challenges and reinforces dominant notions of masculinity. Data from 16 in-depth interviews with former and current Canadian adult male athletes indicate that sport practices privileging forceful notions of masculinity are highly valued, and that serious injury is framed as a masculinizing experience. It is argued that a generally unreflexive approach to past disablement is an extraordinary domain feature of contemporary sport. The risks associated with violent sport appear to go relatively unquestioned by men who have suffered debilitating injury and whose daily lives are marked by physical constraints and pain.

Cette étude examine la façon dont la participation dans un sport physiquement exigeant, avec les risques de blessure et blessures qui lui sont associés, à la fois met en question et renforce les notions dominantes de masculinité. Les données provenant de 16 entrevues avec des athlètes et ex-athlètes masculins canadiens indiquent que les pratiques sportives privilégiant des notions puissantes de la masculinité sont hautement valorisées et que les blessures sérieuses sont perçues comme expériences masculinisantes. Il est avancé qu' une approche généralement irréfléchie face aux blessures antérieures est une caractéristique marquante du sport contemporain. Les risques associés aux sports violents semblent ne pas êtres questionnés par ceux qui ont subi des blessures incapacitantes et dont la vie de tous les jours est empreinte de douleur et de contraintes physiques.

This study focuses on the role that physicality plays in the construction of dominant notions of masculinity and men's health. Through an examination of the centrality of forceful notions of sport in the lives of men, we identify how pain, the risk of injury, and injury itself have come to be accepted as normal components of participation. Our analysis grounds health-promoting and healthcompromising aspects of men's sport within a conceptual framework that considers gendering experiences of sport, body awareness developed through sport, and

Kevin Young is with the Department of Sociology, University of Calgary, 2500 University Dr. NW, Calgary, AB, Canada T2N 1N4. Philip White is with the Department of Kinesiology, McMaster University, 1280 Main St. W, Hamilton, ON, Canada L8S 4K1. William McTeer is with the Department of Physical Education, Wilfrid Laurier University, 75 University Ave. W, Waterloo, ON, Canada N2L 3C5. 
orientations toward health. From in-depth interviews with current and former Canadian male athletes with experiences of injury we show how men learn to disregard risk of physical harm and to normalize pain and disablement as part of the sport experience.

Recent writing in the feminist and sociology of sport literatures has described how modern sport is an institution through which male hegemony is constructed and reconstructed (Bryson, 1987; Connell, 1983; Messner, 1990; Sabo \& Panepinto, 1990; Theberge, 1987; White \& Gillett, 1994; Young, 1993). In this work, the use of force and violence and the tolerance of risk are understood to be valued by many male athletes as masculinizing. This may also be true of pain and injury, which, as Messner (1990) noted, tend to be routine in competitive male sport:

In many of our most popular sports, the achievement of goals (scoring and winning) is predicated on the successful utilization of violence-that is, these are activities in which the human body is routinely turned into a weapon to be used against other bodies, resulting in pain, serious injury, and even death. (p. 203)

Violent sports and disregard for health help reinforce notions of masculinity that are also prized in other social arenas; witness, for instance, the popular iconography surrounding such omnipotent male figures as Clint Eastwood, Arnold Schwarzenegger, Sylvester Stallone, Chuck Norris, and others in contemporary film and video culture (Donald, 1992; Rutherford, 1992). The sporting performances of women, gay men, and men pursuing alternative versions of manliness are, by contrast, trivialized. Our goal, then, is to ask, What is it about dominant notions of masculinity that leads many men to ignore or deny the risk of physical harm?

\section{Physical Power and Symbolic Masculinity}

A starting point for this discussion is the symbolic importance of physical strength and force in sport for an increasingly techno-industrial culture where these characteristics appear to be decreasingly practical in everyday life (Gagnon, 1974). Conversely, violent practices remain taken for granted, considered normal, and even appealing in many contemporary male sports (Morse, 1983; Young, 1993). At both amateur and professional levels of competition, violence, pain, and injury are rationalized by players, coaches, and spectators. Concomitantly, tolerance of risk and injury is reframed and legitimated as a means of impressing coaches (Faulkner, 1973) or as a way of establishing identity and kudos within peer groups (Colburn, 1985; M. Smith, 1975). Such potentially health-compromising norms of masculinist sport are popularized and reinforced by well-known media personalities such as football's John Madden and ice hockey's Don Cherry, both of whom also rationalize violence and lionize players who daringly expose themselves to danger.

The dominant sports creed requires that "real" men play sport in an intensely confrontational manner. As Connell (1983) suggested in his analysis of Australian Rules Football, 
A deft bit of passing, an accurate kick, is cheered by that side's supporters; but the jarring collision of two ruckmen at speed draws gasps and roars from the whole crowd. Among adolescent football players, pure brawn is respected, but not wholly admired. On the other hand, pure cleverness is admired, but slightly condescendingly. (p. 19)

\begin{abstract}
Although there are many exceptions to this pattern according to type of sport, various positional requirements, and player styles, it is common in male-defined sport that willingness to risk injury is at least as highly valued as the demonstration of pure skill. In ice hockey, for instance, the journeyman grinder or the hardnosed "goon" unafraid to "go into the corners" elicits a level of respect rarely awarded to the less physical but more adroit player. Everyday discourses and popular humor are illuminating here. For example, a joke circulating in Canadian ice hockey circles a few years ago targeted Pierre Mondou, a small, skillful player: Pierre's wife, it was said, would not let him vacuum around the house because he would not go into the corners. The meaning of this joke lies in the ridicule leveled at men who do not conform to forceful notions of masculinity. Refusal to be involved in the give-and-take of the rougher aspects of hockey renders Mondou less than fully masculine and, thus, vulnerable to scorn. Tolerance of physical risk, then, carries enormous symbolic weight in the exhibition and evaluation of masculinity (Dubbert, 1979, p. 164). In fact, as Morgan (1992) indicated, in certain milieus men are actually ranked according to the extent of risk acceptance:
\end{abstract}

Masculinity lies not so much in the inevitable associations between strength and gendered power, but in the processes of division and ordering and negotiation whereby distinctions between heavy and light are made and evaluated. (p. 85)

In sport, this distinction often manifests itself in terms of gauging how much a player will "sacrifice" his body for his team.

Where sport is concerned, of course, there is nothing particularly new or novel in this. The link between masculinity and violent sport practices probably has its historical roots in medieval folk games of societies more patriarchally structured and unrestrained in character than their modern counterparts (Dunning, 1986). Some of the more violent traditional sports practices were eliminated following the incorporation of games into the curricula of British public schools in the 18th and 19th centuries, while others such as the developing sport of rugby resisted "civilizing"' trends and staunchly defended an essentially physical version of manliness. These shifts in the meanings of violence found in 19thcentury rugby and other developing British sports have been interpreted as a response to the relative decline of male power in the face of a burgeoning women's movement (Crosset, 1990; Dunning, 1986). Broader historical evidence supports this view and shows how gender relations become strongly polarized during periods of contest and struggle over definitions of legitimate masculinity and femininity (Kimmel, 1987).

Violent contact sports have over the course of the 20th century come to represent "dramatic symbolic 'proof' of the natural superiority of men over 
women' (Messner, 1990, p. 204). As Gillett and White (1992) argued, male physicality in sport is

a subtle form of symbolic domination rather than overt physical control, which contributes to the reproduction and reinforcement of power relations inherent in the existing gender order. (p. 363)

By identifying their bodies as weapons to cause harm and to be harmed, men have championed the physical basis of gender difference (Connell, 1992, p. 736; Messner, 1990; Theberge, 1987). The legitimacy of violent sport stands in opposition to less aggressive and thus less "manly" sports. The symbolic significance of this lies in the association of strength, body size, and aggression with male success. Annexation of physical force and celebration of risk by men more than by women are clearly socially constructed and motivated. As Bryson (1987) suggested, "Small men learn to be tough and aggressive, while even large women rarely do"' (p. 357). Moreover, the monopolization of physicality by men is reinforced elsewhere, as may be witnessed in the normalization of force in other largely male occupational realms such as the police, the military, and the "'heavy" industries (Marx, 1989; Morgan, 1992). Further still, much of the research on the sports media (Hollands, 1988; Sabo \& Curry Jansen, 1992; Young, 1991) shows how masculine hegemony becomes further consolidated as audiences are favorably exposed to sports violence through newspapers, magazines, and television.

Nonviolent sporting practices replete with their " softer" masculine imagery tend to be less valued in male sports culture. Ironically, given the strength requirements of each, sports like figure skating and gymnastics have traditionally been devalued as male pursuits because their aesthetic components are alleged to connote ambiguously masculine, and even feminine, characteristics. The stereotype of the gay male ice skater signifies that nonhegemonic maleness is also subordinate to the more revered kind of masculinity produced through sports like football, ice hockey, and rugby. Of course, the clearest way that healthcompromising sport is consolidated as male territory is through the exclusion of women from sport on the basis that it is too risky (Lenskyj, 1986). Resistance to encroachment by women into the violent, and thus more male-dominated, sports is common, as is evident in the countless debates on whether women and men should play the rougher contact sports side by side or separately (Coakley, 1990). Exclusion of women from sport has historically been rationalized in a number of ways, including arguments that women lack physical requirements, may injure themselves, or may compromise their reproductive abilities, as well as other social psychological myths (Coakley, 1990, p. 191; Lenskyj, 1986). In a particularly striking example of the gendering of risk, Kaplan (1979) described how a Mexican cliff diver justified the exclusion of women from participation:

This is a death-defying activity-men are taking a great gamble to prove their courage. What would be the point if everyone saw that a woman could do the same? (p. 179)

In the next section we use these theoretical ideas to interpret the "body talk" of male athletes. There were many issues to address, including the gendered 
nature of sport practices, orientations toward body image and health, and the relationship between gender and the tolerance of physical risk. In examining these issues, we proceed from the position that social forces work upon male athletes in such a way that they become willing to subject their bodies to injury, but that injury also contains significant meaning in and of itself for participants.

\section{Research Approach}

In the fall of 1992, we interviewed 16 current and former male athletes in southern Alberta and southern Ontario. Semistructured interviews of 1 to 2 hours in length were recorded and subsequently transcribed. We attempted, with only partial success, to interview men from varying social backgrounds. Building a snowball sample from personal acquaintances and contacts, we were unable to explore social class, age, or minority group effects as adequately as we would have liked. All subjects but one were white, all could broadly be categorized as middle-class, and only $25 \%$ of the sample were older than 40 years.

Despite discovering surprisingly little variability in the way each of us "read" the transcribed interviews, we recognize that as with other qualitative work our findings represent our own interpretations of the meanings of sports injury expressed by the subjects. Because of the nature of the methodology, we cannot assert with complete certainty that our interpretations are valid or reliable. However, as three male, former university-level participants in the kinds of aggressive sports our subjects play (football and rugby, specifically), each of us having experience in the "very limiting, often painful downside" of sport (Messner \& Sabo, 1990, p. 14), we feel confident that our decoding of the data is accurate.

Our objective was to examine subjective experiences and meanings attached to sport injuries by men. Although subjects were asked to talk freely about their experiences, a number of issues were addressed consistently in all of the interviews. For example, we asked about subjects' early involvement in sport as children and their relationships with significant others around sport. We also asked about their earliest recollections of sport injury and how these experiences affected their bodies and health, their concepts of self, and their relationships with others.

Because all of the men had experienced an injury serious enough to have altered the course of their lives or to have resulted in some form of disablement, we also wanted them to talk in depth about the short- and long-term experiences and consequences around that trauma. All had experienced very painful injuries, and most had incurred multiple injuries. The aggregate picture represented by a simple injury count among the subjects read like an emergency room nightmare and included fractures to most bones, a ruptured spleen, concussions, a lacerated kidney, a punctured testicle, shoulder and other joint dislocations, torn ligaments, heart attack, and a stroke. Long-term results of these injuries included carpal tunnel syndrome, chronic pain variously located, a removed kidney, partial paralysis, tendinitis, arthritis, and body parts kept in place with braces, plates, pins, and other devices. These subjects, then, clearly represented seriously injured athletes.

We arrived at the interviews with some theoretical questions and propositions emerging from the literature previously discussed. At the same time, we 
remained open to unanticipated constructions of meaning by subjects and to new conceptual ideas. Subjects were allowed to speak in their own terms and categories wherever possible, and systematic analysis of the transcribed interviews yielded a number of themes (summarized as follows).

\section{Early Influences}

We believe that it would be a mistake to ignore the way in which our subjects came to sport. Occasionally, feminist writers have been guilty of assuming rather than showing a connection between sport and the gendering process. In our case, such a connection was clear in two ways.

First, the generational or cyclical nature of male privilege in sport was evident in the manner in which initial contacts with particular sports were made principally through the influence of fathers. Male-to-male influence is a very common, and often taken-for-granted, theme in sports writing. For example, in his 1913 book, Training the Boy, which looks at traditional views on boyhood, McKeever argued that "no boy can grow to a perfectly normal manhood without the benefits of at least a small amount of baseball"' (p. 91). Gagnon's (1974) more recent and critical work similarly conceived of sport as a "way to express male-to-male competitive physical behavior' (p. 145). And even more recently, Kimmel (1990) and Messner (1992) probed male-to-male influence in developing sports character.

In the present study, T_ pushed" him into football, and D__ spoke of his father's need for his son to participate at a very early age:

Well, it really started . . . as sort of a trial-and-error thing. My father wanted me to get involved in sports at a fairly early age. Like, at six years old he was trying to get me into soccer and I think I tried every sport there was for at least a couple of years. And then finally when I turned twelve I got involved in Bantam football, which is like, you know, Little League football and that's when I finally caught on with that. And finally there seemed to be something I was good at so I continued on from there.

While the presocialization influence of some fathers appeared to be a means of enhancing father-son closeness (as M_ said of his early sports experiences, "'It was just something we did together'), other influences seemed altogether less subtle, even coercive. In $\mathrm{T}$ 's words,

My dad had a tough life coming from overseas. He's sort of a perfectionist and if he came to watch and if I screwed up, then after the game he'd let you know about it. He didn't really think, you know, you should be screwing up.

In general, we found that early experiences in sport significantly contributed toward formative gender socialization. Deference to male authority and status seemed quite complete. Tellingly, mothers or female significant others were never mentioned by subjects regarding early influence or initial contact with sport. 
In speaking about physical strength and social roles, Gagnon (1974) argued that in patriarchal culture there "is a steady insistence that young men should be strong, and young women weak' (p. 143). From the interviews we discovered that a second way of demonstrating how sport becomes stratified according to gender norms was to examine how certain sports come to offer meaningful options for young boys looking to develop an essentially robust physical sense of self. For $D_{\ldots}$, now a university football player, this was a matter of connecting with forceful body work:

There's just not a lot of sports around where you can really use your whole body and, you know, engage in destroying another person.

In a quite different way, J___ 's anxieties over body size were ameliorated by the relatively less macho requirements of jogging:

I remember being in high school and I hated my skinny slouched stature because I was interested in football and hockey, and only the big guys did well. I really appreciated my slight stature in running.

Here, we are reminded that it is more accurate to refer to a range of masculinities than merely to refer to a hegemonic/subordinate dichotomy. In sports not requiring force and power, masculinity can also be constructed through traits such as discipline and endurance.

Perhaps most revealingly, M_'s now long-standing career in semiprofessional kickboxing (one of the most violent of all sports) resulted from the rather excessive inducements of a heavy-handed father and his own insecurities vis-à-vis " "not being able to look after" himself:

Being in London, England, during the 1960s and 1970s, being Indian, and being chubby and fat was not the best thing for a lot of reasons. We had problems with racial tensions in the neighborhood we lived in. So my father felt that a way of dealing with that was getting me involved in martial arts, especially since my older sister used to defend me on the street. In our culture it was not a cool thing for your older sister to be defending you. But then I used to look at myself and look at my dad and say, "What do you want me to do?" So he signed me up in martial arts and it was terrible. Training was on Saturday mornings and I used to miss my cartoons. Didn't like it. But he used to drag me out of bed the first three or four years and forced me to go. I hated it. I didn't like it at all.

Speaking of the meaning of sports involvement for men, many of the athletes espoused values and ideas consistent with hegemonic forms of masculinity. This was evident in numerous ways, such as their attitudes to male superiority ("Athletics is the key to the dominance of males,", J___), to injury ("Take it like a man," J___), to players who demonstrate pain ("There's kind of a feeling that's put upon you by your peers; the expression is 'pussy,', ' D___), to their patriarchal rituals ("It makes you more of a guy's guy to be involved in high risk," G__ ), to their impression of how the public sees players of violent sports (" They sort of look up to you because you're handling it,", T___), 
and to what they desire most from sport ("I definitely wanted to get into the physical side of it,' M

In sum, our conversations with male athletes enabled us to understand much more than injury alone. They also helped us see more clearly the extent to which men's sport reproduces what Farr (1988) called "dominance bonding," a system of peer-group-based male privilege integrally linked to the way femininity and masculinity become coded. In what follows, we examine this process in detail by focusing on male athletes' perspectives on injury and pain.

\section{Injury Talk}

Young (1993) argued that, for professional athletes, tolerance of risk is both a central feature of male sports culture and an occupational imperative with practical consequences. While participation for our subjects was not a vocation (only one subject had played sport professionally), physical risk was also central to their experiences since they voluntarily chose to play while injured and suffering from pain.

\section{Pain Principle and Principled Pain}

Because a hegemonic ideal of masculinity is the suppression of affect, continuing to play with pain is viewed as appropriate male behavior. The injured athlete is implored by teammates and/or coaches to "suck it up." He also learns from locker-room slogans, like "you don't make the club sitting in the tub," that tolerance of pain is a rewarded behavior, that it shows character, and that it "separates the men from the boys" (and-by inference-from women and gay men). Sabo (1986) referred to the philosophy of the "pain principle," which includes a set of cultural beliefs or ideological conceptions that prioritize pain over pleasure. We found all subjects conformed to such a philosophy:

Physical pain? Well, it's pretty constant. I have chronic tendinitis in my ankle and a little bit in my shoulder and it's a constant thing. You take a couple of Tylenol every day. For my leg, you take ice and put it in a bag and just put it on there. And it's on there for twenty minutes, you know. It seems to keep things, you know, sort of quiet in there. (D___)

Lately, it's been not too bad. I train with more off days, which gives the wrists a rest. I also avoid activities (such as writing quickly or lots). Right now my fingers in the right hand tingle and occasionally go numb. I stop writing when it gets unbearable, drop my hand down, shake it a lot, and it's OK for another little bit. (I__ )

On the football team you expect your neck to hurt or your back to hurt, and as long as you can keep playing things aren't that bad. I think that's your thinking. And plus after the season things get better. A few weeks later you can start to move your head again. (D__)

In indulging injury and complying with what appears a basic axiom of male sport_-"no pain, no gain" _ athletes have several strategies available to 
them. These strategies are articulated as rules of conduct, or norms, but they also include various techniques of neutralization (Sykes \& Matza, 1989) and other linguistic justifications.

Hidden Pain. Much like using coping mechanisms associated with illness more broadly, some athletes denied their pain, suppressing its physical and mental prescriptions on the body. $\mathbf{J}_{\text {_ _ }}$, for example, risked severe and possible fatal injury by playing football with internal bleeding caused by a ruptured spleen. As he explained, ignoring pain had always been a part of sport for him, even as a child athlete having badly injured his leg:

Then, I responded the same way that I responded with the present injury because I would just try to hide it, and you know the doctors tell you what not to do or not to play or whatever. And I remember playing hockey with the boys, you know, like after school or something, and that I was always goalie. And I remember playing with this broken leg. You know, taking shots off the leg and it would be, you know, right in the shin.

As an adult, J___ still speaks reluctantly of "giving in" to pain and disapprovingly of being "beaten" by it:

I finished the practice and went home. It was at the game the next day, I just tried to eat something and it hurt a lot to eat because of the digestive system, all the gases and stuff inside the stomach didn't mix good. And so I just went to sleep and tried to forget about it and just hoped by morning it would be better. I couldn't really sleep because I couldn't lie on one side or any side and the pain was always really constant and numbing and dull. So the next day I tried to ignore it and tried to play but I just couldn't do it.

Similarly, D___s career as a Canada West track-and-field athlete was one which, as he saw it, depended on constant pain suppression:

I came straight down on my shoulders and one mat was a little higher than the other. So what happened then was I heard a pop. A very, very audible pop and it hurt like hell. And I thought, well, it might only hurt when I land so I'll give it another whirl. You know, see if it was something that just sort of clicked something here or there. I got up and I jumped again and I actually jumped another six or so times and I recall afterwards basically being doubled over and not being able to do anything because it didn't hurt until I hit the mat. And it was kind of bothering me. I generally would go through a real state of denial. And I was doing long jump the same way.

J___ 's views on injury spoke both to a philosophy of hiding pain and to norms requiring that pain not be revealed to football teammates:

I bite my tongue and sometimes if it's really bad I moan once or twice. But sometimes it gets pretty bad and hard to bear. If the guys were around it was a different story but if my girlfriend was there I kind of got more 
sympathy. When I was recuperating, it was hard. When I was starting to rehab, I would grin and bear it.

Rather than being isolated to notoriously rough team sports such as football and hockey, willingness to conceal pain was evident in over 20 sports represented by the subjects, including high jumping, squash, and downhill skiing. The general consensus seemed best summarized by $\mathrm{M}$ who, despite chronic foot pain aggravated by racquet sports, noted, "I sort of live with it. I block it out somehow."

Disrespected Pain. We did not find that athletes in our sample were able to convert pain into pleasure, as some bodybuilders claim to be able to do ( $\mathrm{E}$. Smith, 1989, p. 82). Rather, our conversations demonstrated that injury tolerance is possible because of an attitude of irreverence toward what $\mathrm{K}$ called “"everyday pain.', This was especially evident in the manner several subjects (all football and hockey players) differentiated pain from injury. While the former included, in T__'s words, "mostly soreness and aches" (but which nevertheless often required prescription drug treatment and even surgery), the latter implied either unbearable suffering or manifestly unplayable body conditions, such as broken limb set in a cast.

Like many athletes in the study, D___ had spent several years on painkillers, even having to use them in the off-season to reduce his permanent pain:

We have this term in football. People refer to it as a difference between pain and injury. If you can walk or you can run to any degree, you know, they look at your injury in terms of percentages. If you're at seventy percent and it's better than your second stringer's hundred percent, then you're playing. So, you tend to take a couple of painkillers and tape her up nice and tight and ice before you play, and away you go.

Almost a decade of playing football had led $\mathrm{J}$ to express similar indignation about the routine hazards of his sport:

Last year I ripped my trap and separated my shoulder. . . . Every now and again it flares up and then I take a bunch of Tylenols and forget about that pain. That's probably the most pain I have. But is that injury?

Unwelcomed Pain. That pain is so frequently concealed by athletes is also partly attributable to the fact that it is poorly received by teammates, coaches, and others. In brief, our subjects were critical of the negative impact of injury on teammates and described the display of injury or pain as a "demoralizer":

There's always that pressure because, I mean, you don't want to tell your quarterback you're injured because he'll have reservations about getting you the ball if you're a step slower. Plus it puts more pressure on him because he's got more on his mind. It's a matter of just don't tell anybody else about yourself and just do your job basically. (D__)

In the dressing room before the game, you know, you're there an hour and a half before and if you know someone's hurt and they're showing that 
they're hurt, it kind of brings the other guys down, especially if they're a real leader on the team. If you're kind of whining and you've got the grimace on your face and other people are looking over while you're doing your stretches and stuff and they're going well, you know, what's with this? But you kind of bite the bullet, and you're pumped up and you're ready to go and it hurts but you can't show that it hurts. Then it kind of leads to a higher team morale and it shows that, you know, he's playing for us. ( $\mathrm{J}$

The rules of masculinist sports culture also require that intense pain is controlled and masked. There were several accounts of this. J_ reported that after he broke his leg, the pressure to "play through it" came from peers, his coach, and even his father:

With my femur, I remember vividly just going up the wall and kind of having my head down and getting hit from the side. I know it was my left leg and all I felt was my left leg wrapping around my right leg. Then I fell down. I tried not to show pain and lay there on the ice. I was trying to get up and I remember just falling back down again. And then I remember the coach coming up and trying to help me up and he said, "Come on you can get up," "You're tough," or whatever, and just trying to stand on it, but there was no way. I remember my dad even giving me shit. Even going through the dressing room no one would help me take my equipment off. And we were in a small town and there was no stretcher, so I had to get put in the back of our van and taken to the nearest hospital.

When asked to explain the apparent negligence of those surrounding him, J hinted at the constraints of his "enforcer", role: "No one really thought it was anything serious because . . . of the tough guy label." Similarly, after tearing ligaments in his knee (subsequently requiring reconstructive surgery and a half year of physiotherapy), hockey player $\mathrm{K}$ recalled being told by teammates not to ice the swelling and not to "be a pussy."

Even at the amateur level, being hurt appears to be unwelcomed by coaches. D__ for instance, expressed concerns over his university football coaches' lack of support for his and others' suffering. "Really, they see it as more of an inconvenience.' M_ came by this knowledge more explicitly and recalled several kickboxing coaches telling him not to display any physical distress to them. In the words of one of his coaches, "I'm not bringing a towel to your corner. So don't even bother thinking about stopping.",

Depersonalized Pain. Since pain and injury are perceived to be so poorly received by teammates, athletes often feel a need to rationalize their circumstances privately. This process entails a particular way of thinking and speaking about pain, including the use of certain discursive techniques that result in its depersonalization and objectification.

When "ownership" of pain is acknowledged, it is the local anatomical part, not the body as a whole, which is viewed (in D___s words) as "giving out." Given athletes' generally excellent health and their posture of physical invulnerability, injury is unsurprisingly often understood by players as a form of bodily betrayal and often results in self-resentment. Injured parts assume the 
status of "'other.' In K_'s words, "It's like it's not a part of you. Like it's a totally different portion or something.' As further testimony to this depersonalization process, subjects frequently referred, for example, to an injury of the knee or the shoulder, and were often reluctant to explicitly acknowledge that the injured body part was their own. In general, we found that athletes were humbled, even embarrassed, by the vulnerability of their bodies. This aspect of injury is discussed later in the paper.

As a result of these ways of knowing injury, body damage itself is often articulated through the use of impersonal and techno-rational discourse. Legs become "iced,' knees "scoped,'" ankles "strapped,', aches and pains " killed," and mechanical glitches (pulls, strains, tears, breaks) simply "fixed," often artificially. Remarkably, J__ noted that the pain from his ruptured spleen was " just like squeezing an orange," except rather than juice "a little bit of blood came out." Referring to a skiing accident that resulted in his " actually living on half a kidney . . . one kidney was totally ripped open and the other was lacerated," G___ described his injury as "the equivalent of dropping two eggs on the floor-one cracked, one smashed."

\section{Injury Adjustment}

Efforts to suppress pain and injury, however motivated, are usually limited because the effects of injury are so disruptive in the lifestyles of players beyond sport. Rather than continue to profoundly compromise health, seriously injured athletes ultimately have little choice but to deal with their problems in a practical way. Although at both amateur and especially professional levels the structure of sport contains a medical infrastructure designed to accommodate the physiological and medical aspects of injury (sports medicine clinics, rehabilitation centers, physiotherapy), athletes seldom receive assistance in working through socioemotional side effects, which, ironically, may be even more disempowering. However, while we found socioemotional effects to be profound in the short term, all but two of the men we interviewed ultimately sought out and pursued alternative sports-related avenues for masculine reidentification. Our data suggest, then, that in assessing the relationship between sport, masculinity, and injury, we should distinguish between short-term and long-term adaptations. We do this next by discussing the initially disempowering impact of injury and pain and the subsequent techniques men adopt in order to reframe, and recover from, compromised notions of self.

\section{Disempowered Masculinity}

Dependent as athletes are on physical power and fitness, compromised health often confounds injured male athletes. Injury may involve, among other things, hospitalization, missing competition, social dislocation from the team, even retirement. But equally stupefying for men used to silence around health care and negative bodily change (Rutherford, 1992) are experiences such as unwanted weight gain or loss, feelings of ostracism, and depleted personal worth. In other words, athletes are forced to recognize, perhaps for the first time, that the physical body and its talents are integrally tied to self and to relationships. 
For men who conceive of sport in a principally gendered fashion, then, injury has consequences for the masculine self.

For both triathlete $\mathrm{J}$ and skier $\mathrm{G}$ niggling minor injuries had never been enough to detract from their feelings of invincibility. When asked about taking unnecessary risks, $\mathrm{G}_{\text {_ _ }}$, for example, remembered that there "was a belief that you were bullet proof." So when G hurt his knee and

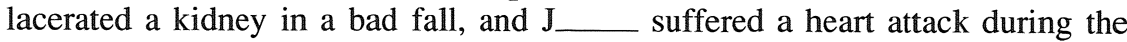
biking leg of a triathlon event, reconceptualizing the place of sport in their lives and their self-images was unavoidable. As J put it, the process was a troubling one to his "inner self": "I've always prided myself on being healthy and strong and it was really confusing feeling weak." For others, coming to terms with injury was similarly demoralizing. $\mathrm{K}$ described his initial response to tearing knee ligaments as "pretty close to the biggest down of my life" and recalled the mental adjustment being "'much tougher'" than the leg pain. D___s broken collarbone was reported as "a very big loss,", and J___'s broken femur was "fully devastating."

Not surprisingly, the magnitude of adjustment problems is often determined by the nature and extent of injury. We found $\mathbf{J}_{\text {___ ' }}$ 's experiences with heart attack during a triathlon event and his subsequent stroke to be highly traumatizing. Not only was he left partially paralyzed and without speech, but his medical difficulties were followed by family breakdown and what $\mathrm{J}_{-}$ described as a "downward spiral" personally:

Funny, I was feeling less of a man. I was married. The doctors inserted a tube in my penis to control the urination and I couldn't control my bladder and I was pissing myself all the time. I felt just inadequate for maintaining my lifestyle with my wife and I suggested to her that we get separated and we did. For me, it was a nonverbal period. I couldn't explain my feelings. It was really frustrating. I felt like a baby. And in the hospital and the physio gym, I couldn't crawl because I'd get sore with my broken rib and my separated shoulder and I couldn't verbalize and I couldn't walk. I just felt like a baby.

J__ was not the only one, however, to understand his injury as demasculinizing in the short term. T for instance, saw his decreasing body mass as a betrayal rendering him "less attractive and less manly" — "you just feel incompetent ... not being able to do things. You just feel helpless." $M$ 's diminished fitness level urged him to try other activities, even gingerly early on, "to try to maintain that image"' of himself. For I_, simply having to adjust to a less rigorous bodybuilding routine because of carpal tunnel syndrome also affected his confidence, self-esteem, and mood. One crucial finding was that the difficulty brought on by adjusting to injury was strongly linked not only to the psychological reassessment anyone might face under similar circumstances but also to notions of truncated male adequacy and role performance.

In general, the short-term effects of injury required a series of physical and mental adjustments, all of them frustrating for men unaccustomed to conceiving of their bodies in any way as weak. These adaptations addressed problems associated with masculine self-image as well as with rehabilitation itself, disengagement from sport, lost training time, and the loss of camaraderie. All athletes lamented 
the latter. Importantly, J___ summarized his own despondency by hinting that while healthy athletes possess active bodies, injured athletes possess less potent or passive ones: "I can't relate to their physical activities anymore, and I felt the silences between us." Despite the fact that his illness occurred some 6 years earlier, J___'s mood when he made these comments remained extremely disconsolate.

Some adaptations were affected by extensive hospital stays and rehabilitation, which provided time for reflection, or what J__ called "soul searching," on the implications of the injury for future participation and lifestyle. Several subjects spoke of being bewildered by the ominous prognoses of doctors cautioning them against repeated risk taking. As previously mentioned, however, while concern for future health tended to be correlated with the type and severity of injury, the fears of all of our subjects for further injury quickly took second place to their desire to return to competition.

\section{Recovered, Reframed, and Unreflexive Masculinities}

Perhaps what is most remarkable about challenges to notions of invulnerability is that on the whole they are extremely short-lived. Despite the severity of these athletes' injuries, all but two returned to essentially risky sports. The two not returning were physically unable to: At the time of this writing, one is still recovering from stroke-induced paralysis, and the other is constrained by only having the use of one half kidney. It appears that the hegemonic model of sport with its emphasis on forceful male performance and its promise of "masculinity validation" (Sabo \& Panepinto, 1990, p. 115) is so meaningful in the lives of some men that injury becomes more constituting than threatening. This may be demonstrated in several ways.

$\mathrm{K} \quad$ 's recovery from knee surgery depended on his overcoming the psychological hurdle of whether he "could take a hit again":

I felt good after I came out of my surgery. I thought I'd worked hard in physio. I thought I could've done basically everything that I could've done to make myself better. People told me that the next year I skated with a limp. I still cross over one way better than the other. I still always turn to one side. That's just something that maybe came out of habit more than anything from being maybe timid on it for the first little while. The best thing that happened to me, I think, was that in the first game I played I just got hammered. I just got nailed. I got up and I felt great. I felt like nothing went wrong and after that I thought that was a big sort of camel's back to get over. I mean it would've worked out better if I had maybe hit the guy, but all in all that was a big step for me.

With the knowledge that he could once more dole out and take pain, $\mathrm{K}$ returned to hockey more confident than ever. This was much the same for J for whom temporary disablement was a catalyst to a stronger, tougher self:

I know that through hard work I can basically overcome anything and I proved that at a young age with my femur. You know, you've broken the biggest bone in your body and it's supposed to be a very serious injury 
and I've never had any, you know, complications with it since. So I knew that through hard work I would be able to come back, and at the end everything would be alright.

Finally, for $\mathbf{J}$ 6 weeks recovering from his spleen injury had shaken his confidence, but only temporarily. His main recollection was how rehabilitation "reenergizes" and provides an opportunity for "a brand new start." Paradoxically, and despite still having to use anti-inflammatory and painkilling drugs frequently, J___ saw his time away from sport as so "reviving" that he returned to football with an even more zealous commitment to the pain principle: "I could even learn to play with a little more pain."

Reframing injury as purposeful appears to result both from the machismo and fatalism of athletes and from the persuasiveness of popular mythology about sport being a character builder. J__'s belief that "everything happens for a reason" was tied to his and others' broader focus on the beneficial attributes of having to deal with the adversity of pain and disablement. When asked how he responded to injury in the short- and long-term, for instance, $T_{\text {__ n noted how }}$ his initial feelings of anger and self-pity were ultimately superseded by a revelation that "in the long run it [injury] will make you a better person." Meanwhile, J__ saw his own "worthwhile" pain as consolidating the way he thought of himself as a man in and out of sport:

I don't think it's really hurt the masculine side at all. If anything, in the long run, it's made me a better person because it's shown that through hard work and being positive you can get through those tough stages and, you know, each day is going to be better. And I think it's made me a better person just knowing that I can work through things like that.

Although not all athletes spoke directly of recovering masculinity from injured bodies and temporarily injured selves, all but one indicated that enduring pain while rehabilitating was linked to self-improvement. For some, this meant redefined philosophical postures (taking slightly less risk, being more prepared, living for more than the moment), but for most it meant regaining bulk, strength, confidence, and self-image - factors all demonstrably tied to reconstructed masculinity in the postinjury context.

The long-term recovery of identity and image after injury is possible because the period of self-reflection following the injury is relatively brief and uncritical. Internal contradictions in the thought processes and discourses of the men returning to sport were evident in the fact that having often reflected on future health immediately following injury, all subjects went on to say that they would change little if they could do it all again. At the time of the interviews, only one athlete had a totally clear bill of health, all but two had returned to competition in very demanding sports, and all of them suffered from residual pain or irreparable damage. In sum, we found these attitudes to be much less critical or reflexive than they were conciliatory toward the dominant code of masculine sport. The latter evidently allows for repeated disregard for physical well-being to be viewed, paradoxically, as constituting. 


\section{Summary and Discussion}

Athletes who demonstrate pain or remove themselves from competition because of injury run the risk of being stigmatized by peers as less than fully masculine, particularly if the injury is not perceived as serious. An athlete's masculinity comes into question when he does not conform to the pain principle. Acknowledging injury except in its most traumatic form indicates that the athlete is succumbing to affect, has not developed sufficient disrespect for pain, or is no longer prepared to sacrifice his body for the team. Moreover, the athlete is also perceived as giving way to parts of himself that are threateningly perceived as "soft" or feminine. In the cult of male physicality, there is an emphasis on doing rather than being, activity rather than passivity. Rutherford refers to this as an emphasis on the "performative" male body (1992, p. 186). By relegating himself to the sideline, the male athlete becomes less functional, and by implication less manly, than his more able teammates. He also compromises the long process of socialization in which sons are taught to be tough, active, and emotionally restrained (Connell, 1983).

Overt and covert pressures are brought to bear on injured athletes to coerce them to return to action. These may include certain "degradation ceremonies" (Garfinkel, 1967, p. 205) such as segregated meal areas, constant questioning from coaches, being ostracized at team functions, or other special treatment that clearly identifies the injured athlete as separate. Pressure placed on the player to return to action before full recovery is in one sense intended to enhance the team's ability to win, but in the process, the long-term health of the athlete is often given little consideration. An alternative interpretation of the ostracism of injured athletes is that the injury reminds those who are uninjured of the likelihood that all athletes will become injured, a reality many athletes and coaches prefer to suppress or rationalize.

Foucault's (1979) ideas on methods of objectification, which emerge principally in the form of discursive regimes, are applicable here in interpreting how men come to value self-domination by disciplining the body through various techniques and cultural practices. Crucially, Foucault's writing on disciplined bodies as objects of power relations hints strongly at the exploitive possibilities of sport:

The body is also directly involved in a political field; power relations have an immediate hold on it; they invest it, mark it, torture it, force it to carry out tasks, to perform ceremonies, to emit signs. (Foucault, 1979, p. 25)

With Foucault, the focus shifts from the promise of empowerment to the regulatory forces of discipline and control, to practices geared toward political, economic, and cultural profit: "The body becomes a useful force only if it is both a productive body and a subjected body" (Foucault, 1979, p. 26). A more poignant example of the relationship between, say, an aggressive, injury-denying football player and the structure of the sport itself would be hard to find.

As previously pointed out by Messner (1990), the injured athlete represents the ultimate paradox of violent sport: The employment of one's body as a weapon inevitably results in violence against one's body. In the context of the current study, this raises important questions about the extent to which traditional sport 
structures actually threaten men's health while promising to augment it. While the subjects in this study showed awareness of the hazards of sports involvement and of pressures to deny pain and injury, there was little acknowledgment that these pressures may be linked to prescriptions of manliness in our culture. Indeed, many subjects were extremely reluctant to recognize sport as "a primary masculinity-validating experience"' (Dubbert, 1979, p. 164), although their accounts provided powerful evidence to the contrary.

Similarly, while the data revealed several cases of what Connell (1992, p. 735) called "father wounds" - overbearing fathers expecting excessive performance standards from their sons-players usually sprang to the defense of fathers and other male significant others when tackled on this matter. Further still, after claiming that injury had led them to redefine the physical expectations of their sports, all who could returned as quickly as their rehabilitation allowed. Many never deviated from their daily menus of lengthy icing treatment, physiotherapy, and painkillers, anti-inflammatory medicine, and other drugs. In brief, not only were athletes' accounts full of internal contradictions, but we found a generally unreflexive approach to past disablement, and a relatively unquestioning posture toward the possibility of future injury.

Continuing involvement following a potentially career-ending injury is part of the gendering of injury. This ultramasculine gesture is accorded even greater status if by returning to action the athlete puts himself at risk to be permanently disabled if he is reinjured. In the professional ranks, Joe Montana, formerly of the San Francisco 49ers, assumed legendary status in North American sport culture by returning from a serious back operation (against medical advice) to lead his team to a 1988 Super Bowl victory, and by returning to the field of play in 1992 after reconstructive elbow surgery. Similarly, in professional ice hockey, Wendel Clark of the Toronto Maple Leafs has become a spectator and media favorite because of his penchant for rough play, his frequent serious injuries, his willingness to play while injured, his "work ethic" during rehabilitation from injury, and his enthusiasm for "the heavy going" upon his return to action.

An important aspect of the violence/injury/masculinity relationship is that it has particular significance for adolescent and young men, for whom the demonstration of adult masculinity is particularly appealing and instructive. Miles (1992, p. 85) referred to "manhood training" through sport, a point picked up in Connell's (1983) observation that

sport is, all considered, astonishingly important. It is the central experience of the school years for many boys, and something which even the most determined swots have to work out their attitude to. (p. 18)

An explanation for how commonplace it is for young males to regard subjecting their bodies to violence as legitimate or natural can be found in the extent to which debilitated ex-athletes tend to remain uncritical of the way that male sport is organized. As Messner (1990) suggested,

To question their decision to give up their bodies would ultimately mean to question the entire institutionalized system of rules through which they had successfully established relationships and a sense of identity. (p. 212) 
What is learned through "injury talk" is the significance of physicality for the hegemonizing of masculinity based on notions of dominance. Plainly, during a period of development when masculinity is most at stake, sport, and particularly aggressive sport, becomes a crucial proving ground for young men. Through forceful contact with other male bodies, the young male is able to deal with anxieties about his own physical maleness, but also to distance himself from all that is considered weak and feminine (White \& Vagi, 1990). It is also apparent that the salience of macho sport declines somewhat in adulthood, and that the decline is a social process (Connell, 1983, p. 22). In the present study, for instance, a reduction in proviolence tolerance and greater introspection toward pain and injury was most obvious with all four athletes over 40 years of age.

We find it intriguing that increasing numbers of former athletes from all levels of expertise are returning to the sports arena, but in contexts that are less violent and have a lower risk of injury. "Old-timer" leagues, "masters" sports competition, and informal activities of a competitive and noncompetitive nature have become popular in recent years. Significantly, these competitions for older athletes are usually less characterized by win-at-all-costs attitudes than are sports events organized for young athletes. Many of the events for older athletes have been modified to reduce the risk of injury (as, for example, in noncontact hockey), which is an ironic critique of the way that modern sport continues to be organized for children and young adults.

This paper adopts a critical approach to the relationship between sport, injury, and masculinity. Conducting a profeminist investigation into the symbolic weight of this relationship for the gender order, we have described decisions and choices made by men in their sports lives. We examined the idea that the social construction of sports injury is linked to the reproduction of male force, which in turn tends to be linked to the broader subjugation of alternative masculinities and femininity. Through the way that males expose their bodies to physical risk, play while injured, and rehabilitate in order to be potentially injured again, it is clear that while males may not actually enjoy physical violence and pain, the rewards of hegemonic masculinity remain meaningful enough.

\section{References}

Adams, S. Adrian, M., \& Bayless, M. (Eds.) (1987). Catastrophic injuries in sports: Avoidance strategies. Indianapolis, IN: Benchmark.

Bryson, L. (1987). Sport and the maintenance of masculine hegemony. Women's Studies International Forum, 10(4), 349-360.

Coakley, J. (1990). Sport in society: Issues and controversies. Toronto, ON: Times Mirror/ Mosby.

Colburn, K. (1985). Honor, ritual and violence in ice hockey. Canadian Journal of Sociology, 10(2), 153-170.

Connell, R. (1983). Which way is up: Essays on sex, class and culture. Sydney: Allen \& Unwin.

Connell, R. (1992). A very straight gay: Masculinity, homosexual experience and the dynamics of gender. American Sociological Review, 57, 735-751.

Connolly, A. (1990, November 15). Sport injuries cost $\$ 1$ billion a year. The Australian, p. 4. 
Crosset, T.W. (1990). Masculinity, sexuality and the development of early modern sport. In M. Messner \& D. Sabo (Eds.), Sport, men, and the gender order: Critical feminist perspectives (pp. 45-55). Champaign, IL: Human Kinetics.

Donald, R. (1992). Masculinity and machismo in Hollywood war films. In S. Craig (Ed.), Men, masculinity, and the media (pp. 124-137). Newbury Park, CA: Sage.

Dubbert, J.L. (1979). A man's place: Masculinity in transition. Englewood Cliffs, NJ: Prentice Hall.

Dunning, E. (1986). Sport as a male preserve: Notes on the social sources of masculine identity and its transformations. In N. Elias \& E. Dunning (Eds.), Quest for excitement: Sport and leisure in the civilizing process (pp. 267-284). New York: Blackwell.

Farr, K.A. (1988). Dominance bonding through the good old boys sociability group. Sex Roles, 18(5/6), 259-278.

Faulkner, R.R. (1973). On respect and retribution: Toward an ethnography of violence. Sociological Symposium, 9, 17-36.

Foucault, M. (1979). Discipline and punish: The birth of the prison. New York: Pantheon. Gagnon, J. (1974). Physical strength, once of significance. In J. Pleck \& J. Sawyer (Eds.), Men and masculinity (pp. 139-149). Englewood Cliffs, NJ: Prentice Hall.

Garfinkel, H. (1967). Conditions of successful degradation ceremonies. In J. Manis \& B. Meltzer (Eds.), Symbolic interaction: A reader in social psychology (pp. 205-213). Boston, MA: Allyn \& Bacon.

Gillett, J., \& White, P. (1992). Male bodybuilding and the reassertion of hegemonic masculinity: A critical feminist perspective. Play and Culture, 5, 358-369.

Hollands, R. (1988). English-Canadian sports novels and cultural production. In J. Harvey \& H. Cantelon (Eds.), Not just a game: Essays in Canadian sport sociology (pp. 213-227). Ottawa, ON: University of Ottawa Press.

Kaplan, J. (1979). Women and sports. New York: Avon.

Kimmel, M. (1987). The contemporary crisis of masculinity in historical perspective. In H. Brod (Ed.), The making of masculinities (pp. 55-67). Boston, MA: Allen \& Unwin.

Kimmel, M. (1990). Baseball and the reconstitution of American masculinity, 1880-1920. In M. Messner \& D. Sabo (Eds.), Sport, men, and the gender order: Critical feminist perspectives (pp. 55-67). Champaign, IL: Human Kinetics.

Lenskyj, H. (1986). Out of bounds: Women, sport and sexuality. Toronto, ON: Women's Press.

Marx, G. (1989). Ironies of social control: Authorities as contributors to deviance through escalation, nonenforcement and covert facilitation. In D. Kelly (Ed.), Deviant behavior: A text-reader in the sociology of deviance (pp. 324-344). New York: St. Martin's.

McKeever, W. (1913). Training the boy. New York: Macmillan.

Messner, M. (1990). When bodies are weapons: Masculinity and violence in sport. International Review for the Sociology of Sport, 25(3), 203-218.

Messner, M. (1992). Boyhood, organized sports, and the construction of masculinity. In M.S. Kimmel \& M. Messner (Eds.), Men's lives (pp. 161-176). New York: Macmillan.

Messner, M., \& Sabo, D. (1990). Sport, men, and the gender order: Critical feminist perspectives. Champaign, IL: Human Kinetics.

Miles, R. (1992). The rites of man: Love, sex, and death in the making of the male. Hammersmith, UK: Paladin. 
Morgan, D. (1992). Discovering men. New York: Routledge.

Morse, M. (1983). Sport on television: Replay and display. In E. Kaplan (Ed.), Regarding television: Critical approaches-An anthology (pp. 44-66). Los Angeles: University Publication of America.

Rutherford, J. (1992). Men's silences: Predicaments in masculinity. New York: Routledge.

Sabo, D. (1986). Pigskin, patriarchy and pain. Changing Men: Issues in Gender, Sex and Politics, 16(Summer), 24-25.

Sabo, D., \& Panepinto, J. (1990). Football ritual and the social reproduction of masculinity. In M. Messner \& D. Sabo (Eds.), Sport, men, and the gender order: Critical feminist perspectives (pp. 115-127). Champaign, IL: Human Kinetics.

Sabo, D., \& Curry Jansen, S. (1992). Images of men in the sports media: The social reproduction of gender order. In S. Craig (Ed.), Men, masculinity, and the media (pp. 169-185). Newbury Park, CA: Sage.

Smith, E. (1989). Not just pumping iron: On the psychology of lifting weights. Springfield, IL: Charles C Thomas.

Smith, M. (1975). The legitimation of violence: Hockey players' perceptions of their reference groups' sanctions for assault. Canadian Review of Sociology and Anthropology, 12, 72-80.

Sykes, G., \& Matza, D. (1989). Techniques of neutralization: A theory of delinquency. In D. Kelly (Ed.), Deviant behavior: A text-reader in the sociology of deviance (pp. 104-111). New York: St. Martin's Press.

Theberge, N. (1987). Sport and women's empowerment. Women's Studies International Forum, 10(4), 387-393.

White, P., \& Gillett, J. (1994). Reading the muscular body: A critical decoding of advertisements in Flex magazine. Sociology of Sport Journal, 11, 18-39.

White, P., \& Vagi, A. (1990). Rugby in the 19th century British boarding school system: A feminist psychoanalytic perspective. In M. Messner \& D. Sabo (Eds.), Sport, men, and the gender order: Critical feminist perspectives (pp. 67-79). Champaign, IL: Human Kinetics.

Young, K. (1991, November 6-9). Writers, rimmers and slotters: Privileging violence in the construction of the sports page. Paper presented at the North American Society for the Sociology of Sport, Milwaukee, WI.

Young, K. (1993). Violence, risk, and liability in male sports culture. Sociology of Sport Journal, 10, 373-396.

\section{Acknowledgments}

We would like to thank Don Sabo, James Gillett, and the editor for helpful comments on earlier drafts of this paper. This study was supported by a grant from Wilfrid Laurier University. 